\title{
Unilateral post-tuberculous lung destruction: the left bronchus syndrome
}

\author{
M Ashour, L Pandya, A Mezraqji, W Qutashat, M Desouki, Naser Al-Sharif,
} A Al-Jaboori, Ali Marie

\begin{abstract}
In a prospective study of 13 patients requiring pneumonectomy for unilateral post-tuberculous lung destruction the left side was found to be affected in 12 . Review of a further 172 cases showed the left lung to have been destroyed in $109(63 \%)$. It is suggested that this predominance of the left side is due to the anatomical characteristics of the left main bronchus and that disordered haemodynamics also appear to play a part.
\end{abstract}

Unilateral total post-tuberculous lung destruction is a well recognised cause of morbidity and mortality. ${ }^{12}$ In Saudi Arabia late presentation and poor compliance with treatment for tuberculosis (as low as $30 \%{ }^{3}$ ) account for an appreciable number of patients presenting in this way, but very few studies have dealt with the problem in detail. ${ }^{4}$ We report the clinicopathological and haemodynamic findings in 13 patients coming to surgery at King Khalid University Hospital. The left lung was affected more frequently than the right, and we discuss the reasons for this predilection.

\section{Patients and methods}

We studied 13 patients with unilateral lung destruction before elective pneumonectomy, by bronchoscopy, bronchography, pulmonary angiography, thoracic aortography, ven- tilation-perfusion scanning, and computed tomography. Indications for surgery included extensive cavitation with persistently positive sputum for six to 15 years (nine patients), repeated large haemoptyses (two patients), and giant bullae (two patients). The resected lungs were submitted for histopathological examination. To assess the prevalence of the condition in the right and left lung, we reviewed the records and radiographs of 1600 patients with proved pulmonary tuberculosis seen during 1983-7.

\section{Results}

The left lung was destroyed in 12 of the 13 patients who underwent surgery (fig 1). Bronchoscopic examination showed stenosis of the right bronchus intermedius in the single patient with destruction of the right lung. There was ulceration of the left main bronchus in two other cases and mucosal thickening and congestion of the left bronchus in four. Pulmonary angiography showed no pulmonary arterial flow on the affected side in any patient (fig 2); thoracic aortography showed bronchial arterial proliferation and systemic inflow to the pulmonary arterial tree from the bronchial circulation (fig 3). Ventilation-perfusion scanning showed no perfusion and poor ventilation.

Total destruction of the parenchyma in each of the resected specimens was apparent from gross examination. The main bronchus in the 12 left lungs was patent, but two had ulcerative
King Khalid

University Hospital,

Riyadh

M Ashour

A Mezraqji

M Desouki

W Outashat

Al-Jaboori

Sahary Chest

Hospital, Riyadh,

Kingdom of Saudi

Arabia

N Al-Sharif

L Pandya

A Marie

Address for reprint requests Dr M Ashour

Department of Surgery,

King Khalid University

Hospital, P Box 7805

Riyadh 11472, Kingdom of Saudi Arabia.

Accepted 21 November 1989

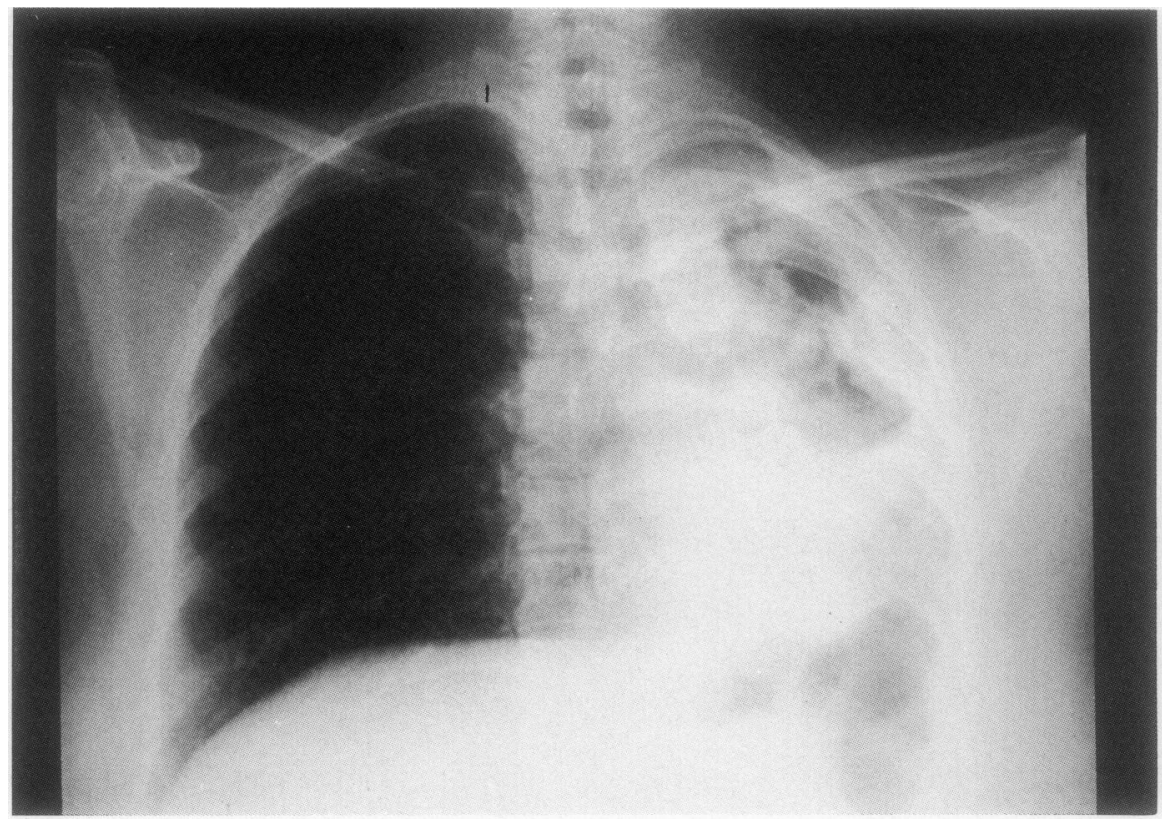

Figure 1 Chest radiograph showing left lung destruction. 
Figure 2 Pulmonary angiogram showing no with lung destruction. pulmonary flow on the side

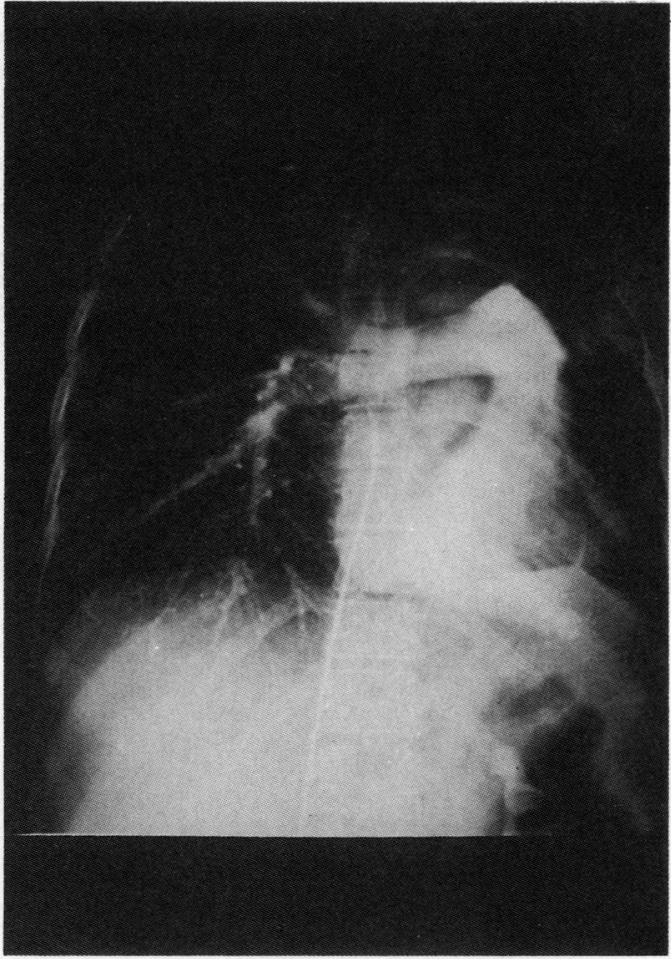

lesions and in one of these the ulceration was continuous with a parabronchial tuberculous mass. In the single right sided specimen the bronchus intermedius was stenosed. Histologically, there was extensive active tuberculosis with fibrosis, widespread cavitation, and bronchiectasis. The lymph nodes from three specimens were examined; tuberculous granulomas were found in one case but only carbon pigmentation in the other two. Obliteration of pulmonary arteries and endarteritic changes were seen in the fibrocaseous areas. Bronchial arteries were dilated and patent.

In the 1600 cases of pulmonary tuberculosis that were available for review, we considered

Figure 3 Thoracic aortography showing systemic inflow to the pulmonary artery from the bronchial circulation.

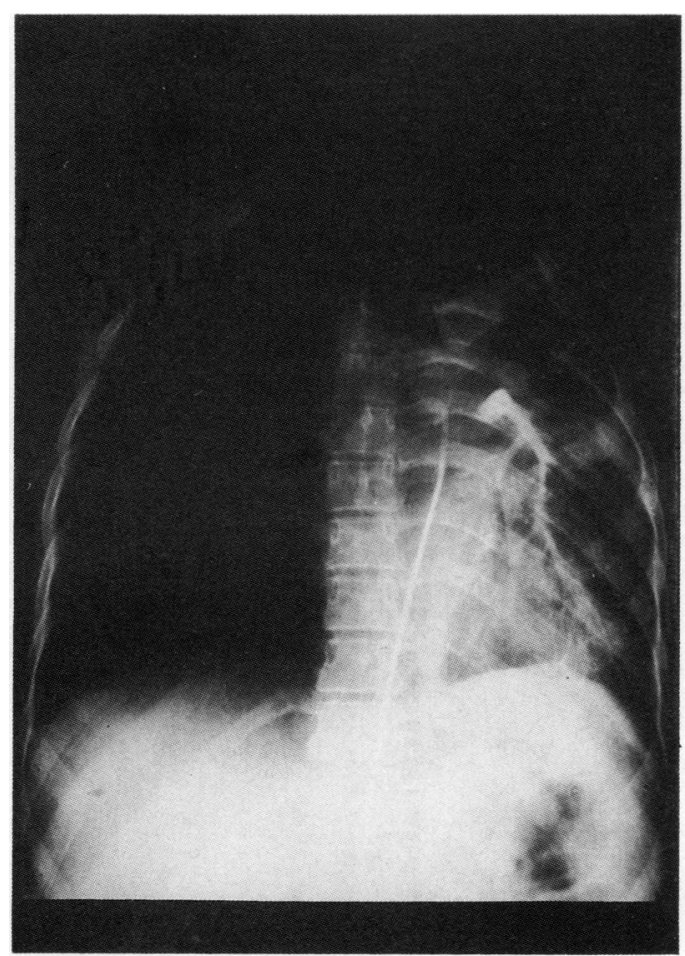

post-tuberculous lung destruction to have been present in $172(11 \%)$. The left lung was destroyed in $109(63 \%)$ and the right in 63 $\left(37^{\circ} \%\right)$.

\section{Discussion}

Although the apical and posterior segments of the upper lobes are the site of predilection with about equal incidence on the two sides, ${ }^{5}$ total lung destruction is more frequent on the left. A combination of anatomical factors may make the left lung more vulnerable to this type of damage, and disordered haemodynamics also appear to play a part.

The left main bronchus is considerably longer and about $15 \%$ narrower than the right, ${ }^{67}$ and the peribronchial space is limited by its proximity to the aorta, ${ }^{8}$ so that it is more prone to obstruction by enlargement of adjacent lymph nodes. Such obstruction was not evident in the lungs we examined, probably because we were seeing the end stage of the disease process-it is likely to have been present in the initial stages because mediastinal and hilar node enlargement is common in African and Asian patients with post-primary tuberculosis. ${ }^{910}$ In addition, the more horizontal course of the left main bronchus than of the right may have an effect on drainage of secretions, ${ }^{11}$ as has been shown recently by bronchoscintigraphy. ${ }^{12}$

Several studies have shown that pulmonary haemodynamics play a part in the pathogenesis and spread of tuberculous infections. The characteristic localisation of pulmonary tuberculosis seems to be associated with lymph stasis secondary to reduced arterial flow at the apex and also with increased oxygen tension at that site. ${ }^{13}$ Pulmonary arterial flow is reduced or absent when there is bronchial obstruction, ${ }^{14}$ stasis of secretions, ${ }^{15}$ or parenchymal infection. ${ }^{16}$ Ligation of the pulmonary artery of patients ${ }^{17}$ and experimental animals ${ }^{18}$ with pulmonary tuberculosis is reported to exacerbate the disease, as does anastomosis of a major systemic vessel to the pulmonary artery. ${ }^{19}$ In our patients angiography showed pulmonary arterial flow to be absent, bronchial arteries were prominent, and there was radiological evidence of systemic flow into the pulmonary arterial tree. It seems likely that these factors led to lymph stasis and a raised oxygen tension, favouring progression of the disease and eventual lung destruction.

1 Cockshott $\mathrm{P}$, Middlemiss $\mathrm{H}$. Clinical radiology in the tropics. Edinburgh: Churchill Livingston, 1979:160-2.

2 Adebnojo SA, Adebo OA, Osinowa O, Grillo IA. Management of tuberculous destroyed lung in Nigeria. $J$ Natl Med Assoc 1981;73:39-42.

3 Aneja KS. Assignment report of World Health Organization tuberculosis in Saudi Arabia. Geneva: WHO, 1984.

4 Onadeko BO, Awotedu AO. Destroyed Lung Syndrome. An end stage dilemma in patients with pulmonary tuberculosis 5 year experience in a teaching hospital in culosis. A Tuberculosis World Conference on Tuberculosis and ResTuberculosis World Conference on Tuberculosis and Res-
piratory Disease. Singapore: 1986 . piratory Disease. Singapore: 1986. plawol TM, Onadeko BO, Sofowora EO. Radiologic patterns of pulmonary tuberculosis in Nigeria. Tropical and Geographical Medicine 1975;27:339-50.

6 Hollinshead WH. Anatomy for surgeons. Vol 2. New York: Harper and Row, 1979:44-51.

Last RJ. Anatomy, regional and applied. London: Churchill Livingstone, 1978:226-7.

8 Williams PL, Warwich R. Gray's Anatomy. 36th ed. London: Churchill Livingstone, 1980:1241-7. 
9 Humphries MJ, Nun AJ, Byfield SP, et al. National survey of tuberculosis notification in England and W.ales in 1983: characteristics of disease. Tubercle 1987;68:19-32.

10 Kent DC, Schwartz R. Hilar lymphadenopathy in tuberculosis. Am Rev Respir Dis 1967;96:435-9.

11 Leigh Collis J, Clark DB, Aby Smith R. d'Abreul's Practice of cardiothoracic surgery. London: Edward Arnold, 1976:107-21.

12 Groth S, Mortensen J, Lange P, et al. Imaging of airways of bronchoscintigraphy for the study of mucociliary clearance. Thorax 1988;48:360-5.

13 Goodwin RA, Des Perez RM. Apical localisation of pulmonary tuberculosis, chronic pulmonary histoplasmosis and progressive massive fibrosis of the lung. Chest 1983; 83:801-5.

14 Grant JL, Naylor RW, Crandel WB. Bronchial adenoma resection with relief of hypoxis pulmonary vaso-constric- tion. Chest 1980;77:446-9.

15 Gordon I, Helms P, Fazio F. Clinical application of radionuclide lung scanning in infants and children. $B r J$ Radio 1981;54:576-85.

16 Charles BT, Rama R. Lung imaging -unilateral absence or near absence of pulmonary perfusion on lung scanning. Semin Nucl Med 1983;13:388-90.

17 Rienhoff WF Jr. A clinical analysis and follow-up study of 502 cases of carcinoma of the lung. Dis Chest 1950;17: 33-54.

18 Scott J, Hanlon CR, Olson BJ. Experimental tuberculosis (2). Effects of ligation of pulmonary artery in tuberculosis in monkeys. $J$ Thorac Surg 1950

19 Rollins C, Hanlon HW, Scott Jr, Olson BJ. Experimental tuberculosis: effects of anastomosis between systemic and pulmonary arteries on tuberculosis in monkeys. Surgery 1950;28:209-24. 